\section{OP13 EVALUATING EXPERIENCES OF ADVANCE CARE PLANNING FACILITATORS: RESULTS FROM THE INTERNATIONAL ACTION STUDY}

\begin{abstract}
1,2 CA Christensen* ${ }^{*}$ 1,2 M Adsersen, ${ }^{2,3} \mathrm{AT}$ Johnsen, ${ }^{4} \mathrm{~J}$ Seymour, ${ }^{5} \mathrm{~F}$ Bulli, ${ }^{6} \mathrm{~B}$ Cerv, ${ }^{7} \mathrm{~L}$ Deliens, ${ }^{8} \mathrm{~A}$ Van der Heide, ${ }^{8} \mathrm{~K}$ Korfage, ${ }^{6} \mathrm{U}$ Lunder, ${ }^{9} \mathrm{~K}$ Pollock, ${ }^{10} \mathrm{NJ}$ Preston, ${ }^{7} \mathrm{MN}$ Verkissen, ${ }^{11} \mathrm{M}$ Zwakman, ${ }^{1,2} \mathrm{M}$ Groenvold. ${ }^{1}$ University of Copenhagen, Copenhagen, Denmark; ${ }^{2}$ Bispebjerg and Frederiksberg Hospital, Copenhagen, Denmark; ${ }^{3}$ University of Southern Denmark, Odense, Denmark; ${ }^{4}$ University of Sheffield, Sheffield, UK; ${ }^{5} I S P O$, Florence, Italy; ${ }^{6}$ University Clinic for Respiratory and Allergic Diseases Golnik, Golnik, Denmark; 'Vrije Universiteit Brussel (VUB) and Ghent University, Brussels, Belgium; ${ }^{8}$ Erasmus Medical Center, Rotterdam, Netherlands; ${ }^{9}$ University of Nottingham, Nottingham, UK; ${ }^{10}$ Lancaster University, Lancaster, UK; ${ }^{11}$ University Medical Center Utrecht, Utrecht, Netherlands
\end{abstract}

10.1136/spcare-2019-ACPICONGRESSABS.13

Background The ACTION trial evaluates the effect of the ACTION Respecting Choices (RC) advance care planning (ACP) intervention in patients with advanced cancer in six European countries. Systematic evaluations of such ACP conversations by facilitators are currently lacking. We developed and applied a 10-item facilitator-reported instrument.

Methods The instrument asked about the facilitator's perception of the patient's and the personal representative's (PR) reactions to and engagement with the intervention and satisfaction with the intervention.

Results From March 2016 until February 2018, 272 conversations took place. Of these, 265 were evaluated. According to the facilitators, $32 \%$ of the patients did not appear to understand all questions asked (29\% understood most, $3 \%$ understood about half), and $36 \%$ were not able to answer all questions (31\% answered most, 4\% answered about half, $1 \%$ answered fewer). Furthermore, $38 \%$ of the patients and $27 \%$ of the PRs did not appear to perceive all questions as $\mathrm{OK}$ (patients: $33 \%$ perceived most as $\mathrm{OK}$, 3\% about half, 2\% fewer; PR: 24\% most, 3\% about half). Facilitator perception of patient satisfaction, PR satisfaction and their own satisfaction with ACP conversations ranged 40-54\% for 'very much', 41-49\% for 'quite a bit' and 5$11 \%$ for 'a little'.

Conclusion To our knowledge, this is the first clinical trial to systematically evaluate the feasibility of ACP conversations from the facilitator perspective. Parts of the ACP intervention appeared to be challenging for patients and PRs. These results, together with qualitative data, will help understand the outcomes of the ACTION trial.

Funding EU's FP7.

\section{OP14 EFFECTS OF IMPLEMENTATION OF A STANDARDISED PALLIATIVE CARE PATHWAY FOR PATIENTS WITH ADVANCED CANCER IN A DUTCH HOSPITAL}

${ }^{1} \mathrm{~A}$ Van der Padt - Pruijsten, ${ }^{1} \mathrm{M}$ Leys, ${ }^{2} \mathrm{~A}$ van der Heide, ${ }^{2} \mathrm{C}$ Van der Rijt. ${ }^{1}$ Maasstad ziekenhuis, Rotterdam, Netherlands; ${ }^{2}$ ErasmusMC, Rotterdam, Netherlands

\subsection{6/spcare-2019-ACPICONGRESSABS. 14}

Background Early integration of oncology and palliative care has been recommended as a major strategy to improve patient outcomes at the end of life. A standardised palliative care pathway(PCP) may be useful to support such integration. We studied whether implementation of a PCP had an effect on place of death, hospitalisations, and documentation of advance care planning.
Methods In a single centre pre- and post-intervention study, data were collected for adult patients with cancer who had been treated at inpatient or outpatient clinics and died between February 2014 and February 2015 (pre-PCP period) or between November 2015 and November 2016 (post-PCP period).

Results 852 patients were included, 426 in each study period. The PCP was used for 237 patients (56\%) after implementation. The PCP was started 33 days (IQR 12-74days) before death. $76 \%$ and $77 \%$ of the patients died outside the hospital in the pre- and post-PCP period, respectively $(p=0.57)$. No differences were found for hospitalisations in the last 3 months of life. In the pre-PCP period, bad-news conversations $(75 \%$ and $62 \%$ respectively, $\mathrm{p}<0.001)$ and preferred place of death $(47 \%$ and $32 \%$ respectively, $\mathrm{p}<0.001)$ were documented more often, whereas a DNR code was more often documented during the post-PCP period $(79 \%$ and $89 \%$ respectively, $\mathrm{p}<0.001)$.

Conclusions A high percentage of patients died outside the hospital in both groups, not increased by implementation of the PCP. Start of a PCP in the last two months of life may be too late to facilitate ACP.

\section{OP15 PATIENTS' READINESS FOR ADVANCE CARE PLANNING CONVERSATIONS: A QUALITATIVE STUDY AS PART OF THE ACTION STUDY}

${ }^{1} \mathrm{M}$ Zwakman, ${ }^{1} \mathrm{MM}$ Milota, ${ }^{2} \mathrm{~A}$ Van der Heide, ${ }^{2} \mathrm{U}$ Jabbarian, ${ }^{2} \mathrm{IJ}$ Korfage, ${ }^{2} \mathrm{JAC}$ Rietjens, ${ }^{1} \mathrm{JJM}$ van Delden, ${ }^{1} \mathrm{MC}$ Kars. 'University Medical Center Utrecht, Utrecht, Netherlands; ${ }^{2}$ Department of Public Health, Erasmus MC, Rotterdam, The Netherlands

\subsection{6/spcare-2019-ACPICONGRESSABS.15}

Background Patients and healthcare professionals describe patients' readiness for advance care planning (ACP) as an indicator for whether or not to start ACP conversations. Nevertheless, it is unclear how readiness manifests and develops throughout an ACP conversation. This study explores patients' readiness during an ACP conversation.

Methods A qualitative study using content analysis of structured ACP conversations between a trained facilitator, a patient with advanced colorectal or lung cancer and a relative. Conversations were conducted in the Netherlands as part of the international ACTION trial. Analysis was supported by NVivo 11.

Results Transcripts of thirteen ACP conversations were included. All patients expressed both signs of not being ready and being ready within one conversation. Signs of being ready included answering questions on a personal level or demonstrating a realistic understanding of one's disease. Signs of not being ready included limiting one's perspective to the here and now or indicating a preference not to talk about an ACPrelated topic. Signs of not being ready were especially seen when future oriented topics such as 'complications' and 'hope' were discussed. Patients could more easily elaborate on less future orientated topics as 'good life' and 'earlier experiences with illness'. Despite signs of not being ready patients were able to continue the conversation.

Conclusion Patients do not have to be ready for all elements of ACP to be able to participate in an ACP conversation. Healthcare professionals should be aware of patients' ability to alternate in readiness depending on the topic that is discussed. 